high. However, those few seeds that do escape can look forward to a healthy future. Ecology http://doi.org/bp5t (2016)

\section{CONSERVATION BIOLOGY}

\section{Lazy bustards live longer}

Migration in great bustards seems to be on the decline because many of those that do migrate die in collisions with power lines.

Carlos Palacín at the National Museum of Natural Sciences in Madrid and his colleagues captured and radiotagged 180 male great bustards (Otis tarda) across 29 breeding groups, covering most of the species' range in Iberia. Only some birds migrated north in summer. Of those that did, $21.3 \%$ died in crashes with power lines, whereas just $6.3 \%$ in the sedentary group died in this way.

The authors found a steady increase in the proportion of non-migratory males over the study period, from $17 \%$ in 1997 to $45 \%$ in 2012 . They propose that males decide whether to migrate by observing other males. Thus, as the number of migrators declines, the behaviour may die out. Conserv. Biol. http://doi.org/bp53 (2016)

\section{PALAEONTOLOG}

\section{Tiny pterosaurs' tenure extended}

The discovery of a surprisingly small fossilized pterosaur (pictured with domestic cat for scale) in rock some 77 million years old challenges the accepted history of the winged reptiles. Scientists had thought that, by around 100 million years ago, small pterosaurs had been replaced by larger species.

Elizabeth Martin-

Silverstone at the University of Southampton, UK, and her colleagues uncovered a wing bone and vertebrae from a pterosaur in 80-million- to 72-million-year-old rock formations in British
Columbia, Canada. Although the creature's 1.5-metre wingspan was tiny compared with that of the 10-metre giants known from this period, bone analysis revealed that it was almost fully grown.

Fossilized juveniles of larger pterosaur species from this period are also rare, suggesting that the record may be biased against small pterosaurs. R. Soc. Open Sci. 3, 160333 (2016)

\section{STEM CELLS}

\section{Bone cells on demand}

Researchers have come up with a simple recipe for making bone from stem cells.

Embryonic stem cells can form every type of tissue in the body, but methods for forcing these and other pluripotent stem cells to differentiate into a specific type can be inefficient and costly. A team led by Shyni Varghese at the University of California, San Diego, added a chemical called adenosine which occurs naturally in the body - to human stem-cell cultures and produced bonemaking cells called osteoblasts in under three weeks. The cultured osteoblasts generated calcified bone, and scaffolds that had been coated with the osteoblasts and implanted into mice repaired skull defects.

Sci. Adv. 2, e1600691 (2016)

\section{GENETICS \\ Synthetic DNA overreacts to light}

Synthetic DNA bases created in 2014 to expand the genetic code are light-sensitive and produce reactive oxygen species (ROS) when exposed to certain wavelengths.

Ultraviolet light can

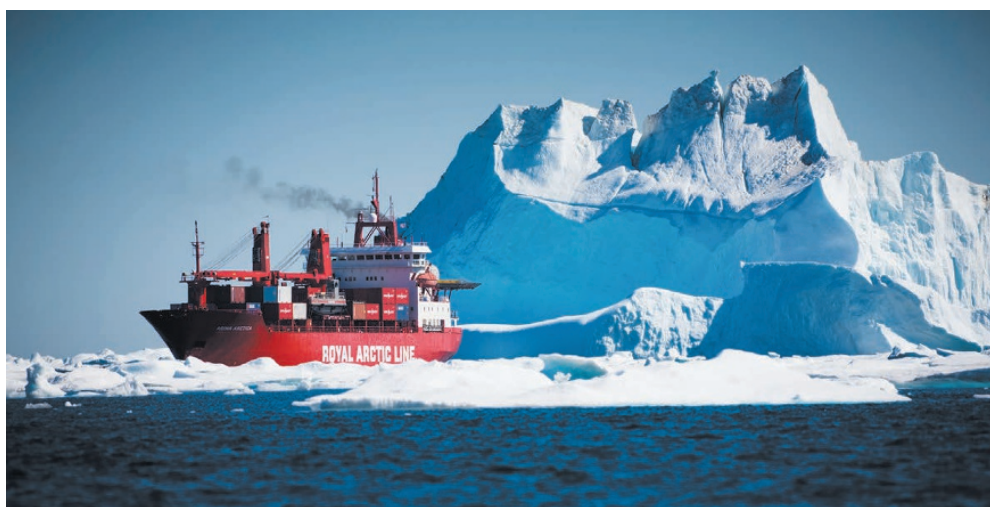

damage natural DNA bases, but cells have in-built repair mechanisms to fix this. Carlos Crespo-Hernández of Case Western Reserve University in Cleveland, Ohio, and his co-workers found that two labmade DNA bases - d5SICS and $\mathrm{dNaM}$, which have been used to design semi-synthetic bacteria - generate up to 100 times more reactive species than the most reactive natural base, thymidine, when exposed to near-visible wavelengths of light. In response to light exposure, a carcinoma cell line grown with d5SICS had higher levels of ROS, and cell proliferation was reduced.

Synthetic DNA bases may accelerate photochemical damage to cells, the authors say. J. Am. Chem. Soc. http://doi.org/ bp55 (2016)

\section{CLIMATE CHANGE}

\section{Melting ice opens Arctic to shipping}

Thanks to melting Arctic sea ice, ships with moderate ice strengthening (lighter than currently required, pictured) may be able to travel northern waters all year round by the century's end.

Nathanael Melia and his colleagues at the University of Reading, UK, used several global climate models to simulate the fastest shipping routes through the Arctic, depending on future greenhouse-gas emissions. In their most extreme scenario, the route from Yokohama in Japan to Rotterdam in the Netherlands becomes 13 days shorter than alternative routes by 2100 .

Even ordinary vessels could see the period during which they can navigate Arctic waters double by mid-century.

Geophys. Res. Lett. http://doi. org/bp5x (2016)

\section{Star-rich early galaxy clusters}

Galaxy clusters in the early Universe produced more stars than their more modern counterparts.

When a galaxy becomes part of a cluster - a group of galaxies bound together by gravity - its crowded surroundings often cause it to stop producing stars, an effect called environmental quenching. Using the Keck Observatory in Hawaii and the Very Large Telescope in Chile, a team led by Julie Nantais at the Andres Bello University in clusters nearly 10 billion years old. They found that, in these early clusters, only about $30 \%$ more of the galaxies had stopped producing stars than had the surrounding galaxies, compared with a difference of about $50 \%$ in newer clusters.

Knowing how quenching changes over the history of the Universe may help scientists to determine why the cluster environment causes the phenomenon.

Astron. Astrophys. 592, A161 (2016)

\section{DNATURE.COM}

For the latest research published by Naturevisit:

www.nature.com/latestresearch Santiago observed four galaxy 